\title{
PERFILES AXIOLÓGICOS SOBRE LA NATURALEZA NORMATIVA A PROPÓSITO DE LA EFICACIA Y LA EFICIENCIA EN MATERIAS FUNDAMENTALES PARA LA SUPERVIVENCIA . EL CASO DE LAS NORMAS VOLUNTARIAS DE GESTIÓN AMBIENTAL
}

\author{
THE REGULATORY NATURE OF AXIOLOGICAL PROFILES REGARDING THE \\ EFFICIENCY AND EFFECTIVENESS IN KEY AREAS FOR THE PLANET'S SURVIVAL. \\ THE OBSERVANCE OF VOLUNTARY ENVIRONMENTAL MANAGEMENT \\ STANDARDS
}

\begin{abstract}
María Méndez Rocasolano
Doctor en Derecho Universidad Complutense de Madrid . Full Bright by Harvard. Director del Departamento de Derecho Constitucional y Ambiental. Universidad San Antonio de Murcia UCAM. E-mail: mmrocasolano@gmail.com

Luis Alberto Marín Gonzalez

Doctor en Derecho por la Universidad Católica San Antonio de Murcia. E-mail: luis.marin@economistas.org
\end{abstract}

Convidados

RESUMEN: En el marco de la globalización, de la sociedad de la ligereza y carente de valores, propio de la modernidad líquida hay ciertos sectores como el turismo, quepor las implicaciones económicas y ecológicas que posee, concreta un ámbito de estudio idóneo para proponer medidas eficaces y eficientes desde la estructura jurídica, tanto normativa como institucional que procurenun desarrollo humano y ecológicamente sostenible. Para ello se propone la incorporación de la nota de obligatoriedad a normas con características propias, como son las de los sistemas de gestión ambiental de las estructuras productivas, aplicando los criterios axiológicos y de fundamentación jurídica con la intención de procurar una eficaz y real protección del medio natural como base esencial de la dignidad y de la vida humana.

Palabras clave: Derecho Constitucional, Fundamentación Axiológica, Hart, Sistemas de Gestion Medioambiental ; Desarrollo sostenible, Derechos al medio ambiente , Dignidad de la persona. Dinamogénesis de los valores.

ABSTRACT: In the context of globalization, of the society of the lightness and devoid of values, characteristic of liquid modernity there are certain sectors such as tourism, which by economic and ecological implications that it has, a field of study suitable to propose effective and efficient measures from legal, both normative and institutional structure that seek human and environmentally sustainable development. This proposes the incorporation of compulsory standards with characteristics note, such as systems of environmental management of the productive structures, applying the criteria axiological and legal foundation with the intention to ensure a real and effective protection of the natural environment as essential dignity and life human. 
Keywords: Constitutional law, axiological Foundation, Hart, environmental management systems; Sustainable development, environment, human dignity.Dinamogenesis of values.

CONTENIDO: Prenotandos 1. Aproximación teórica a la incorporación de la nota de obligatoriedad a las normas voluntarias de gestión ambiental en el sector del turismo . 2. Validez, la obligatoriedad y la eficacia del derecho en el caso del medio ambiente. 3. Dinamogénesis de los valores como vía para concretar la posibilidad de incorporar la nota de obligatoriedad a las normas voluntarias de gestión ambiental en el sector del turismo

\section{PRENOTANDOS}

Las siguientes consideraciones que el lector tiene en sus manos forman parte de un diálogo ${ }^{1}$ multidimensional donde se traban realidades y posibilidades dibujando una tela de arañaen torno a la protección ambiental. Desde tres puntos,se delimita el primer hilo formado por las opiniones deMÉNDEZ ROCASOLANO, de MARÍN GONZALEZ, y de HART donde los fundamentos económicos, los constitucionales y los filosóficos cierran un análisis concéntrico a la necesaria actuación individual y colectiva en defensa y protección de la Naturaleza. Hoy dicha tarea se muestra esencial para la supervivencia de nuestra especie. La mencionada multidisciplinariedad que dibuja la segunda dimensión del trabajo se completa con una visión axiológica, eficaz y eficiente del Derecho como herramienta al servicio de la humanidad.

Ciertamente cuando hablamos de Naturaleza, medio ambiente o recursos naturales topamos con expresiones multidisciplinares y poliédricas donde si no fijamos un punto de referencia antropocéntrico,el discurso jurídico no tiene sentido ${ }^{2}$. Ello define el precepto ambiental desde una "cualificación finalista" en cuanto a la clase de medio que se pretende. La norma que lo regula deberá estar acompañada por una habilitación general a los poderes públicos para potenciar y exigir actividades en el buen uso y protección de medio ${ }^{3}$.

De los derechos humanos de la llamada tercera generación, el derecho a un medio adecuado para el desarrollo de la persona, es junto al derecho a la paz uno de los grandes protagonistas de los retos jurídicos del presente siglo.

Se sitúa alrededor de los años 70 el interés por la protección ambiental, que con el transcurso de los últimos años del pasado siglo y las primeras décadas del presente se ha ido integrando en el mundo jurídico a todos los niveles, desde el internacional al local, con una progresiva toma de conciencia del significado del vínculo indisoluble y las interrelaciones que los elementos anteriores tienen respecto al concepto de medio ambiente y su conexión con el sector industrial y económico ${ }^{4}$. En Europa actualmente la normativa ambiental se referencia desde la

\footnotetext{
${ }^{1}$ El presente artículo está recogido también por la amable invitación de Paulo BONAVIDES en su Revista Latinoamericana de Estudios Constitucionales, presenta el diálogo entre director y autor del último capítulo de la Tesis Doctoral de Luis Alberto MARÍN GONZALEZ bajo la dirección de la Doctora MÉNDEZ ROCASOLANO, que con el título Protección ambiental, turismo y eficacia productiva bajo el parametro de la validez jurídica y la sostenibilidadexaminan aspectos vinculados a las preocupaciones jurídicas y ecológicas de la actualidad.

${ }^{2}$ Esta versión antropocéntrica en España adecua el medio ambiente con el desarrollo de la persona conectándolo con la calidad de vida mediante la utilización racional de los recursos naturales. De hecho, así se indica en su expresión normativa fundamental, la del derecho consagrado en el artículo 45 de la Constitución española que lo adjetiva estableciendo el término de derecho a un medio ambiente adecuado para el desarrollo de la persona. Al respecto de la necesidad de tener a la persona como referente MARTIN MATEO,se refiere a la condición inevitablemente antropocéntrica del derecho en MARTIN MATEO, Ramón,El hombre una especie en peligro, Campomanes, pags 89 a 90 .

${ }^{3}$ GÁLVEZ MONTES,“Comentario al artículo 45 de la Constitución”, en Comentarios a la Constitución. Dirigidos por GARRIDO FALLA,Civitas 2a edición,Madrid,1985pág 812

${ }^{4} \mathrm{Al}$ respecto véase NAREDO,J osé Manuel,"El proceso industrial visto desde la economía ecológica” en Economía Industrial : El reto industrial del medio ambiente (1),Centro de Publicaciones del Ministerio de Industria y energía ,Madrid, Agosto -septiembre 1991 págs 67 a 81. LLEONART Y AMSELEM realiza un estudio en el que divide el Revista de Direito Brasileira | São Paulo, SP | v. 19 | n. 8 | p. 70 - 83 |Jan./Abr. 2018
} 
sostenibilidad y se vincula la acción de la sociedad y la productividad a un necesario equilibrio con el medio natural. ${ }^{5}$

Por su parte la descripción de la estructura alcance y aplicaciones de las normas de gestión ambiental en sus modalidades de ISO y del reglamento comunitario EMAS ponen de manifiesto que con las herramientas y procesos tanto de producción como de gestión,a pesar de no fijar metas ambientales ni determinar mínimos en las emisiones o inmisiones contaminantes, consiguen la reducción de recursos naturales en las fases productivas y el fomento de consumo de productos verdes o ecológicos, lo que supone una indudable protección ambiental en la fase de prevención 6 .

Superando la separación entre los extremos del mundo empresarial e industrial y el medio ambiente, no debe olvidarse que el fiel de la balanza no está en equilibrio. Ciertamente, la tensión se reduce como consecuencia de la normativa ambiental, la preocupación y conciencia ecológica e iniciativas como las de las normas de gestión ambiental que incorporan al coste de producción el respeto por el medio. ${ }^{7}$ La vinculación de las preocupaciones de salud y ambientales a las actividades empresariales las hacen más competitivas y atractivas a los consumidores cuando a través de las normas de gestión ambiental optimizan y mejoran su procesos productivos reduciendo el impacto ambiental negativo en el medio y los recursos naturales.

Ello se manifiesta en los criterios que guían su aplicación, que pasan por la obtención de una mejor gestión ambiental, el desarrollo de un interés por los standares ambientales, han de ser aceptablemente viables en relación con el coste de producción, el criterio innovador y la flexibilidad, elementos que son fundamentales en estas normas no prescriptivas, así como su control que se manifiesta en que han de estar sujetas a verificación tanto interna como externa y fundamentalmente han de ser útiles y utilizables por cualquier estructura empresarial con independencia de su tamaño o dedicación.

En este entramado socioeconómicodeun mundo globalizado que discurre por la frivolidad de la sociedad de la ligereza de LIPOVETSKYdentro de un marco más amplio de lo que BAUMAN con acierto ha denominado la modernidad líquida hay ciertos sectores como el turismo, que por las implicaciones económicas y ecológicas que posee, concreta un ámbito de estudio idóneo para proponer medidas eficaces y eficientes desde la estructura jurídica, tanto normativa como institucional que procurenun desarrollo humano y ecológicamente sostenible.

El sector turístico, sin olvidar el impacto negativo de carácter antrópico que opera sobre el medio natural, constituye un factor de desarrollo económico. Aplicando herramientas como las que ofrecen los sistemas de gestión ambiental que consiguen reducir los impactos y aplicar medidas de promoción y mejora de los medios naturales degradadosplantea un escenario donde se esbozeteóricamente la posibilidad de incorporar la nota de obligatoriedad a las normas de carácter voluntario.

Lógicamente se tiene pleno conocimiento de las dificultades y objeciones que pudieran hacerse a esta posibilidad que algunos dirían que violenta la legitimidad democrática de los

estado de la cuestión en tres periodos. El primero lo situa entre 1952 y 1962 que a su entender son los años decisivos en la concienciación ambiental. La segunda etapa al cifra en la siguiente década (1962.1972) donde se realiza una diversificación de objetivos y finalmente, la tercera etapa la situa entre el año 1972 y el año 1974 donde se producen las nuevas estrategias. LLEONART Y AMSELEM, Alberto.J, Derecho de los Estados a disponer libremente de sus recursos naturales, "Estudios internacionales”. Serie 1 Problemas actuales. nº7).Consejo Superior de Investigaciones Científicas, Instituto Francisco de Vitoria. ,Madrid, 1976 págs 392 a 408.

${ }^{5}$ Ejemplo claro de estas consideraciones son la ley de economía sostenible y las actuaciones dirigidas a la separación de residuos y reciclaje fomentado por políticas de los gobiernos europeos de la última década, dentro estpsel ejemplo más notorio son los programas de desarrollo dentro del marco 20 /20 de la Unión Europea .

${ }^{6}$ En este sentido destacan las consideraciones de CAIRNCROSS que indica que se plantean como "el desafio del gobierno y de los ambientalistas es enfocar métodos para desarrollar los incentivos correctos de forma que las industrias los consideren lucrativos y baratos.

7 La implementación de la normativa de gestión ambiental asegura el cumplimiento de la normativa ambiental y posee un efecto promotor de las compañías, sus productos y servicios en el mercado global.

Revista de Direito Brasileira | São Paulo, SP | v. 19 | n. 8 | p. 70 - 83 |Jan./Abr. 2018 
ordenamientos jurídicos y nos sitúa en una antinomia insalvable. Es por ello necesario explicar en estas líneas primeras que las siguientes consideraciones se circunscriben al ámbito puramente científico de estudio de posibilidades teóricas que diseccionenla idea propuesta poniendo de manifiesto tanto los elementos que la imposibilitan como aquellos que la podrían hacer viable.

\section{APROXIMACIÓN TEÓRICA A LA INCORPORACIÓN DE LA NOTA DE OBLIGATORIEDAD A LAS NORMAS VOLUNTARIAS DE GESTIÓN AMBIENTAL EN EL SECTOR DEL TURISMO}

En el ámbito jurídico existen determinaciones que dotan de valor, coherencia y sistematicidad al Derecho como conjunto de normas e instituciones que regulan la vida en sociedad, dentro de ellas la lógica fija el discurso para dotar de validez las consideraciones del propio Derecho. Desde las reflexiones sobre el significado y alcance de la ciencia del Derecho que hundían sus raíces en las disposiciones divinas para mantener la paz en la organización de un grupo humano hasta la actualidad donde en Harvard se estudian posibilidades de derechos y obligaciones extraterrestres y derechos fundamentales de ciborgs es propio de la reflexión jurídica una potencia que la anima, la de los valores que pretenden la mejora de la vida y la convivencia humana bajo postulados de Justicia.

En el ámbito del humanismo iusnaturalista donde los valores encuentran un papel fundamental y fundamentador del Derecho ${ }^{8}$, planteamos un ejercicio de reflexión teórica sin desdeñar otras posturas iuspositivistas cuyo análisis y discurso exceden del objetivo de la temática que nos ocupa.

Para incorporar la nota de obligatoriedad a las normas voluntarias de gestión ambiental en el sector del turismo en primer lugar estudiaremos la posibilidad de las aporías en el ámbito jurídico que, igual que en la física cuántica, hace que ser y no ser al mismo tiempo sea posible, para lo que nos apoyaremos en una humilde revisión de la validez, la obligatoriedad y la eficacia del derecho en el caso del medio ambiente. En segundo lugar utilizaremos la dinamogénesis de los valores de MENDEZ ROCASOLANOpara concretar la posibilidad de incorporar la nota de validez con el ánimo de proponer una posibilidad para reducir los impactos que el turismo procura al medio natural.

\section{VALIDEZ, LA OBLIGATORIEDAD Y LA EFICACIA DEL DERECHO EN EL CASO DEL MEDIO AMBIENTE}

Como es de todos conocido, las normas regulan múltiples aspectos de la vida del hombre, podría decirse que son pocas las actividades que están fuera de su alcance, organizan la sociedad con dictados que dentro de los sistemas democráticos representan el querer de la mayoría de la soberanía popular. Así, los Estados usan las normas para promover, ordenar y establecer un sistema pacífico de convivencia donde el derecho da solución a los conflictos que genera la vida en sociedad. Desde ROSSEAU la validez del cuerpo normativo en los Estados democráticos se fundamenta en el desarrollo del pacto social que nivela la tensión entre la libertad y el poder con la seguridad y la paz social como referentes.

En el caso que no ocupa, la supervivencia del hombre y la humanidad se incorporan a las finalidades que el Derecho poseía tradicionalmente9. Efectivamente la protección de los

\footnotetext{
${ }^{8}$ Sobre el iusnaturalismo crítico, iuspersonalista y comunitario CfrLUCAS VERDÚ, Pablo,"Dimensión axiológica de la Constitución" en Anales de la Real Academia de Ciencias morales y Políticas,año XLIX, n74, Curso académico 96/97,Madrid, págs 143 a 150.

9 Para revisar la Finalidad el Derecho remito a LUIS PRIETO SANCHIS ," Fines el Derecho y satisfacción de necesidades.A propósito de una razón práctica sobre intereses genraliable"s, en Funciones y Fines del Derecho Revista de Direito Brasileira | São Paulo, SP | v. 19 | n. 8 | p. 70 - 83 |Jan./Abr. 2018
} 
ecosistemas, finalidad última del derecho ambiental viene determinada por una visión antropocéntrica del Derecho que determina la consciencia del lugar que el homo sapiens sapiens tiene en la Naturaleza y su vínculo vital con ella. La consciencia a principios el siglo XX de la finitud de los recursos naturales y la verificación científica de los resultados que la contaminación ejerce en los diferentes habitats del planeta han dado carta de naturaleza a la necesidad de establecer reglas de comportamiento en relación con el medio en el que las sociedades se $\operatorname{asientan}^{10}$. En un primer momento, se prestó atención a los entornos que no habían sido transformados por el hombre entendiendo que estos espacios por su características y singularidad debían conservarse o gestionarse de forma tal que no se ejerciera sobre ellos la degradación que la contaminación o el impacto antrópico implicaban ${ }^{11}$. En este sentido MENDEZ ROCASOLANO, explica como a lo largo de todo el siglo anterior se ha ido dando una suerte de transformación en el planteamiento de la cuestión y como consecuencia de los datos que la realidad viene arrojando se ha dado un cambio de paradigma que entiende como natural todo lo que el planeta contiene. La aceptación de este planteamiento tiene consecuencias revolucionarias en el modo de entender el mundo y la vida. Podemos decir que estamos en los albores de un cambio radical en las formas de relacionarnos con el entorno.

Si el fiel de la balanza se inclina hacia la incorporación de medidas reales y efectivas de respeto por la Naturaleza, puede haber una esperanza poniendo la razón, la inteligencia y la creatividad humana al servicio de la restauración y recuperación de la Tierra, si al contrario continuamos con un impacto exponencialmente consumidor de recursos y multiplicador de residuos, la Naturaleza se adecuará haciendo solo viable la supervivencia de los más fuertes de nuestra especie ${ }^{12}$.

Estas consideraciones establecen los parámetros bajo los cuales se van a examinar la validez, la obligatoriedad y la eficacia de la normativa ambiental, hace no tanto tiempo hubiera que haber probado con datos y mediciones la veracidad de las afirmaciones arriba indicadas, hoy convivimos con tales verdades hasta tal punto que resulta cotidiano y de todos conocido el efecto invernadero, la reducción de la biodiversidad, el deshielo de los polos y la contaminación de las aguas.

En este estado de la cuestión no se propone dentro del sistema normal de producción normativa estructuras que constriñan la voluntad fuera del sistema democrático, sino se propone la asimilación de nuevas formulaciones a través del impulso que las reglas principiales, promotoras, interpretadoras y potenciadoras de los valores ambientales. La adhesión a la axiología aquí es manifiesta.

En sentido positivista HART con un claro influjo de KELSEN maestro delateoría Pura del Derecho y la visión práctica que el utilitarismo británico comporta mantiene una perspectiva

Estudios en honor de Profesor Mariano Hurtado Bautista, Universidad de Murcia, Secretariado de Publicaciones 1992.

${ }^{10}$ En este sentido debemos de indicar todo la normativa ambiental, en los ámbitos internacional, comunitario, estatal , autonómico y local, respecto a las sctuaciones de la economía destacan las consideraciones de BILLÓN CURRÁS,Margarita, en "Comercio y medio ambiente en los paises de la OCDE" en Economía Industrial : El reto industrial del medio ambiente (1),Centro de Publicaciones del Ministerio de Industria y energía ,Madrid,Agosto septiembre 1991 págs 51 a 65.

${ }^{11}$ PEREZ MORENO, Alfonso, “Tensión medio ambiente y desarrollo económico. Ordenación del territoio y medio ambiente.Espaciosnaturales”en Protección administrativa del medio ambiente, Dir. J.L Requerolbañez. Consejo General del Poder Judicial,Septiembre,Madrid,1994.

${ }^{12}$ Explicaciones de la Doctora MENDEZ ROCASOLANO en el curso de Derecho Ambiental en la Universidad Católica San Antonio de Murcia en el año 2016. En este sentido es recomendable la lectura de PEREZ MORENO, Alfonso, "Tensión medio ambiente y desarrollo económico. Ordenación del territorio y medio ambiente .Espacios naturales”en Protección administrativa del medio ambiente, Dir. J.L REQUERO IBAÑEZ. Consejo General del Poder Judicial, Septiembre, Madrid,1994.

Revista de Direito Brasileira | São Paulo, SP | v. 19 | n. 8 | p. 70 - 83 |Jan./Abr. 2018 
socialdemocrática que se conjuga con la realidad de nuestro tiempo, haciéndose el autor y sus consideraciones actuales y oportunas en nuestro diálogo con el autor ${ }^{13}$.

A continuación nos adentramos en el estudio de la posible incorporación del carácter de obligatoriedad a las normas de carácter voluntario que como las de la ISO 14.000 procuran una efectiva protección ambiental. Ciertamente las normas jurídicas están formadas tanto por un supuesto que es la descripción e un hecho, una actuación o actividad o su omisión y la disposición que en la norma indica un resultado en forma de consecuentes derechos y obligaciones que se derivan del mencionado supuesto.

La aplicación normativa puede ser pública o privada, siendo el segundo caso el que nosinteresa. En el caso de las normas privadas no hay una parte dispositiva en la que una autoridad impone las consecuencias, su ejecución a lo sumo se hace de forma privada entre iguales, no existiendo la capacidad sancionadora que caracteriza a las normas públicas, que se ven auxiliadas por los cuerpos y fuerzas de seguridad del Estado en la misión de hacer cumplir con las normas.

Podemos indicar sin temor a equivocarnos que son más efectivas y eficaces ${ }^{14}$. Se ha elegido a HART para dar motivos que superen los obstáculos normativistas y sistemáticos que entienden que el Derecho es un conjunto de normas organizadas independiente de cualquier contenido ético y con una débil relación con los valores o la moral. Como las teorías de KELSEN, el ser y el deber ser no deben de estar relacionados. ${ }^{15}$

De la mano de Cristina FUERTES PLANES que hace una magnifica condensación del pensamiento del filósofo el derecho británico más importante del siglo XX, para proponer la incorporación de la obligatoriedad a las normas de gestión ambiental se han de incorporar al Derecho, para ello partamos en primer lugar del sistema de fuentes, para establecer si sería posible y cómo incorporarlas y en segundo cúal sería su naturaleza y alcance, con la intención de mostrar que si bien en el caso del Derecho ambiental la necesidad de la supervivencia, inspira los valores ecológicos que el Derecho incorpora a través de la normas, la realidad demuestra que son ineficaces e insuficientes.

Nos preguntamos si dotando de obligatoriedad a instrumentos extrajuridicos que garantizan una producción y desarrollo ecológico y afectan al corazón del sistema empresarial, en concreto la normativa voluntaria de gestión ambiental en el sector del turismo se podría recuperar la eficacia de la normativa ambiental ${ }^{16}$.

El planteamiento seria el siguiente expresado en forma de silogismo

\footnotetext{
${ }^{13}$ A obra más conocida de Herbert LionesAdolphus HART, es The concept of law, ClarendonPress 1961, aquí se ha consultado la tradución de R CARRIO 2 edición .Ed Editora Nacional de Mexico de 1980 . De sus múltiples publicaciones se han tenido en consideración "¿Hay derecho naturales?” En "Derecho y Moral contribuciones a su analisis, Traducido también por Genaro R CARRIO, editado por Depalma en 1962. "El nuevo desafio al positivsimo jurídico" en "Sistema n 36 1980, págs 3-18 traducido por L HIERRO y F LAPORTA y J. R PARAMO y "Derechos NatuarlesBentahm T John StuardMill" en Anuario de Derechos humanos n ${ }^{\circ} 3$ y J. R PARAMO 1985, págs 137162.

${ }^{14}$ Sirva de ejemplo la fijación de un límite de velocidad en una urbanización privada como consecuencias del órgano de decisión y el reglamento de seguridad vial que indica las velocidades máximas. Infringidas ambas normas mientras que no hay sanción en forma de multa ni retirada de puntos por parte de la empresa de seguridad privada es evidente que si la habrá cuando los agentes de las guardia civil de tráfico realicen la misma operación.

${ }^{15}$ En opinión de KERCHOVE, a través de Cristina FUERTES PLANES, cuyo artículo "Validez, obligatoriedad y eficacia del derecho en H.L.A.HART, en Anuario de Derechos humanos. Nueva EpocaVol 8 págs 131-186, 2007, sirve de referente y guía a todo el punto que estamos desarrollando. La cita se corresponde con la nota 2, pag 133. KERCHOVE,. M. y OST, F: El sistema jurídico entre orden y desorden trad. I Hoyo Sierra Servicio de publicaciones de la Facultad de derecho Universidad Complutense de Madrid 1997. Pág 61.

${ }^{16}$ En el estudio del medio como bien económico es interesante la lectura de uno de los primeros artículos sobre el tema de Gabriel SOLÉ VILLALONGA, "Problemática económica en la defensa del medio ambiente" en Conservación del medio ambiente, Revista de la Universidad Complutense $n^{\circ}$ 105, septiembre-octubre 1976,Madrid, págs 49 a 61.
} 
1. El impacto del hombre en la Naturaleza la está degradando y el Derecho ambiental intenta protegerla imponiendo normas de conducta que la evidencia pone de manifiesto que son ineficaces porque van en contra del modelo económico y productivo actual. En el caso de España y en concreto en el sector del Turismo el impacto antrópico es supercontaminante pero genera desarrollo económico y social (puestos de trabajo).

2. Existen herramientas que impulsadas por los criterios de diferenciación competitiva y eficacia y eficiencia productiva determinan la gestión ambiental en la empresa, a través de un sistema de diagnosis, actuación por objetivos y metas bajo el marco de una política ambiental. Con la implementación de estos procedimientos que están sometidos a un control continuo se cumple con la legislación ambiental. En el caso del Turismo la implementación de sistemas de gestión ambiental en las empresas aseguran el cumplimiento con la legislación ambiental.

3. La implementación de sistemas de gestión ambiental pueden actuar como mecanismo de eficacia para el Derecho ambiental en tanto limita la actuación empresarial al cumplimiento de la normativa ambiental en vigor. En el caso el turismo, implementación e de sistemas de gestión ambiental en toda la cadena del sector turístico supondría el cumplimiento de todas las normas referentes a la protección ambiental lo que establecería una protección ambiental real y efectiva.

La cuestión reside es si esto posible jurídicamente. La regla de reconocimiento que determina el sistema de fuentes de un ordenamiento jurídico, tiene un "núcleo de buen sentido"17 (en el caso del Derecho natural) que contiene las "señas de conducta" que toda organización social tiene que contener para ser viable. Tales reglas constituyen de hecho, un elemento común al derecho y a la moral convencional (o social) de todas las sociedades que han alcanzado el punto en que uno y otra se distinguen como formas de conducta universalmente conocidas (...) tales principios de conducta universalmente conocidos, que tienen una base en verdades elementales referentes alos seres humanos, a sus circunstancias naturales y a sus propósitos pueden ser considerados como el contenido mínimo del Derecho Natural. La finalidad última es la superviencia y las condiciones en las que esta se da. ${ }^{18}$ Para HOBBES será una obligación moral previa a la obligación de la norma y que supone el contenido básico del deber de cumplir el pacto político ${ }^{19}$ (la obligación), se encuentra en el fin o bien que ha de tenerse en cuenta ${ }^{20}$.

Con HART superanado las relaciones causa efecto delas normas, se buscan las razones para aceptar u obededecer voluntariamente las normas y exigencias del ordenamiento jurídico, así como los parámetros que hagan razonables su finalidad en conexión directa con los valores que fundamentan su validez. En este sentido, ALEXY ${ }^{21}$ REALE $^{22}$ y en España los constitucionalistas de la escuela de Salamanca con LUCAS VERDÚ como referente mantienen la vinculación entre Moral y Derecho como elementos de una misma realidad en una relación de interdependencia bajo el parámetro de validez jurídica.

\footnotetext{
${ }^{17}$ HART ObCitpág 330

${ }^{18}$ Indica HART " que los hombres en general desean vivir es un mero hecho contingent e que podría ser de otra manera, y que todo cuanto podamos querer decir al calificar la supervivencia de meta o fin humano es que los hombres efectivamente la desean El concepto de derecho pagina 330.

${ }^{19}$ Resulta fundamental revisar el concepto de obligación basado en el pacto social del HOBBES. En este sentido la obra de H WARRENDER, thepoliticalphilosophy of Hobbes. His theory of obligation. Oxford 1957 representaun notable exponente.

${ }^{20}$ Pág 238 -239.HART mantiene una visión teológica de la naturaleza y en este sentido indica que no es lo bondadosa que se mantiene, recordemos que el estado natural presenta una faceta de crueldad bárbara frente a la debilidad.

${ }^{21}$ ALEXY Robert: El concepto y la validez del Derecho ,Gedisa,Barcelona, 1994.

${ }^{22}$ REALE Miguel, O direito como experiencia, Saraiva, Sao Paulo 1968 pág 100 y ss. Véase también Pablo LUCAS VERDÚ Estimativa y política constitucional. Ed Facultad de derecho; servicio de publicaciones Complutense 1979.
}

Revista de Direito Brasileira | São Paulo, SP | v. 19 | n. 8 | p. 70 - 83 |Jan./Abr. 2018 
Así pues podemos indicar que la validez del derecho conecta directamente no sólo con la forma en que dentro del sistema de fuentes surgen las normas dentro del ordenamiento jurídico, también de acuerdo con el contenido, cuya validez se considera por la mayoría, intrinsecamente valioso.

Respecto a la obligatoriedad, cuestión ampliamente debatida con criterios actuales a lo largo de todo el siglo XIX donde el porqué debe cumplirse el derecho abre las ventanas de la fundamentación hermética del potitivismo, ésta surge de la validez. Desde la explicación que KELSEN da a la Grundnormquesupone el constreñimiento a una actuación dirigida a preservar aquello que la sociedad estima valioso contenido en la norma fundamental, hasta posiciones situadas en el iusnaturalismo, todas ellas coinciden en la necesidad de criterios de validez y organización sistémica del Derecho.

La textura abierta del Derecho, aceptada por toda la doctrina, hace a FUERTES LA PLANA indicar de las reglas que son "criterios o pautas a seguir para que la solución del caso, y en, particular, la decisión interpretativa sea valida. ${ }^{23}$ La clasificación tradicional de IHERING de normas de conducta y normas de sanción, para HART normas primarias que imponen deberes y secundarias de potestad, respecto a las primarias (normas de reconocimiento, de cambio y de adjudicación) dotan de sistematicidad al Derecho. La regla de reconocimiento de HART (Rule of recognition) es la que establece la validez y permanencia de las normas en el sistema jurídico ${ }^{24}$.

Esta regla "solo existe como practica compleja, pero normalmente concordante, de los tribunales, funcionarios y particulares, al identificar el Derecho por referencia a ciertos criterios.Su existencia es una cuestión de hecho". ${ }^{25}$ Así para el británico, no toda norma existente es válida, aunque toda norma valida es existente, en este sentido nos apoyamos en FALCON Y TELLA ${ }^{26}$ cuando indica que decir que Derecho obligatorio no significa que sean jurídicas solo las normas que de un modo $\mathrm{u}$ otro, directa o indirectamente impongan obligaciones.

En el caso de las normas voluntarias relativas a los sistemas de gestión ambiental nos encontramos, por una parte en que están cargadas de un contenido existencial concreto y que es incorporación de herramientas y procesos dentro de la actividad empresarial que consiga una mejor y mayor eficacia productiva en equilibrio (como mínimo y mejora de los recursos y el medio natural. En este sentido la profesora de Filosofía de la Complutense indica "la efectividad es un concepto formal, que solo implica que se cumpla lanorma. En cambio la eficiencia tiene contenido material, al conllevar que se logre el fin perseguido por dicha norma" 27

Así pues parece que podría justificarse el planteamiento de incorporación de la obligatoriedad, es decir la obediencia a este tipo de normas cuya validez resulta probada desde la perspectiva de la eficacia y eficiencia de laprotección de los valores que las inspiran. De esta forma FUERTES-PLANA indica que aparece una situación en la que HART mantiene la existencia de un Derecho como sistema normativo en el que los ciudadanos se encuentran ante la norma no en unasituación de "tener una obligación" sino de la de "verse obligado".

\footnotetext{
${ }^{23} \mathrm{Ob}$;.CitPág 150.

${ }^{24}$ El concepto de regla de reconocimiento, ha sido ampliamente estudiado por la doctrina, su tratamiento oportuno sería el de un estudio concreto y detallado por el significado y alcance que posee, aquí únicamente referimos algunos autores que han reflexionado sobre su contenido, advirtiendo que la dimensión de una apropiada reflexión sobre la rule of recognition superaría totalmente el discurso que se mantiene y el objetivo de la presente investigación. Alf ROSS y Joseph RAZ la entienden como hecho sociológico, las consecuencias de no poseer sanciones es estudiada por paramo arguelles en JRL A HART y CRACOGNA Regla de reconocimiento y norma básica en "Hart y el concepto de Derecho" en Revista de Ciencias sociales, Valpariso n 281986 cit por LA FUENTE,pag 173 y ss.

${ }^{25}$ Hartobcitpag 137.

${ }^{26}$ MarñaiJose FALCON Y TELLA: Concepto y fundamento de la validez del derecho, Madrid ,Civitas 1994, pag 49 y ss.

${ }^{27}$ FALCON Y TELLA obcitpag 58.

Revista de Direito Brasileira | São Paulo, SP | v. 19 | n. 8 | p. 70 - 83 |Jan./Abr. 2018
} 
Las consideraciones sobre las normas principiales de DWORKIND en la década de los 80 del siglo pasado enriquecieron las aportaciones de HART sobre las normas que forman parte del sistema jurídico y los criterios de validez, existencia y obligatoriedad.

La concepción del Derecho que mantenemos se adhiere a la visón sistemática de LUHMAN $^{28}$ que lo entiende como un sistema autopoietico y dinámico que da soluciones adecuándose a las necesidades sociales que la historia y la cultura demanda. Así, en el caso que nos ocupa dentro del marco democrático, son los valores del desarrollo sostenible los que fundamentan el movimiento de las herramientas jurídicas que aseguren tal finalidad ${ }^{29}$. De manera tal que en el caso del Turismo se establezcan modelos de equilibrio entre la protección ambiental y el desarrollo económico que la sociedad en su mayoría demanda.

A continuación veremos cómo podría ser posible a través de la utilización de la dinamogénesis de los valores de la Profesora MENDEZ ROCASOLANO.

\section{DINAMOGÉNESIS DE LOS VALORES COMO VÍA PARA CONCRETAR LA POSIBILIDAD DE INCORPORAR LA NOTA DE OBLIGATORIEDAD A LAS NORMAS VOLUNTARIAS DE GESTIÓN AMBIENTAL EN EL SECTOR DEL TURISMO}

A partir de la teoría tridimensional por la que el derecho tiene tres dimensiones vinculadas entre sí : hecho, norma y valor ${ }^{30}$ como hemos visto líneas arriba y con el ánimo de procurar una posibilidad para reducir los impactos que el turismo ocasiona al medio natural, revisamos a continuación como es posible incorporar la nota de obligatoriedad cuando una expresión normativa como la normas de la familia ISO 14000 expresan valores que la sociedad demanda y que la razón impone al estar ligados a la supervivencia del hombre. De la mano de DEL VECCIO para quien "una idea preliminar se encuentra implícita en todas las doctrinas del jusnaturae : que el Derecho responde a una necesidad del hombre y es inseparable de la vida humana Ubi homo ubijus de forma que "no sólo debe proteger a la persona en su existencia material, sino también en su ser espiritual; es fácilmente comprensible que el maestro concluya que tienen carácter jurídico aquellas relaciones vitales que se verifican entre diversos sujetos e implican una correlación de sus voluntades, aunque

"les falten algunos elementos exigidos por las leyes positivas para su validez,... como tales relaciones son reales y surgen con ocasión de aquellas mismas exigencias reconocidas y consagradas por las normas jurídicas positivas, no pueden ser simplemente ignoradas por éstas, ni colocadas sin más en la categoría

\footnotetext{
${ }^{28}$ LUHMAN Norberto, El enfoque sociológico del derecho en "anales de la Cátedra Francisco Suarez n 251985 páginas 93 y siguientes en ellas se dedica a explicar que pese a ser un sistema cerrado posee elementos de apertura a los condicionamientos sociales. Respecto a la referencia cultural, Véase la Ciencia del derecho como ciencia cultural en LUCAS VERDÚ, Pablo: Teoría de la Constitución como Ciencia Cultural. 2ªedición. Dykinson, Madrid,1998 .

${ }^{29}$ Acerca del significado del reconocimiento del derecho a un medio sano y susu relaciones con el desarrollo sotenible concebido como derecho humano Cfr CANÇADO TRINDADE Antônio Augusto, "Environment and Development: Formulation and Implementation of theRighttoDevelopment as a Human Right" en Derechos humanos,Desarrollo Sustentable y Medio Ambiente, $2^{\text {a }}$ edición Instituto Interamericano de Derechos Humanos ,San José de Costa Rica,1995, págs 39 a64. Realizando un defensa de la globalidad como la vía en al que se realizan los valores de los derechos económicos sociles y culturales destca la aportación de ORDOÑEZ, Jaime, en "Derechos Humanos y Globalidad: Notas para una perspectiva Holística y Sistémica” en Derechos humanos ,Desarrollo Sustentable y Medio Ambiente, $2^{\mathrm{a}}$ edición Instituto Interamericano de Derechos Humanos, San José de Costa Rica,1995, pág 159 a 162.

${ }^{30}$ Aconsejo la consulta de REALE, Miguel,Teoría tridimensional do direito,EdiçaoSaravia,Sâo Paulo,1968.Para el autor "el derecho es un hecho, una obra humana, estimulada por la conciencia de unas necesidades en la vida social, obra producida bajo la forma normativa; y que en su función para satisfacer esas necesidades intenta hacerlo de acuerdo con la realización de unos valores específicos.
}

Revista de Direito Brasileira | São Paulo, SP | v. 19 | n. 8 | p. 70 - 83 |Jan./Abr. 2018 
de lo ilicito, sino que deben ser reconocidas de algún modo en cuanto a su existencia y en cuanto a los efectos que normalmente producen. Adviértase en esto la labor incesante y al crisis perpetua del derecho positivo, que teniendo necesidad de una base dogmática para sostenerse, es conducido por la naturaleza misma de las cosas a superar en cierto modo sus propios dogmas, para reunir en una más amplia esfera de verdad aquellos principios de donde ha surgido y que permanecen, en sí mismos, inagotables"31

En este marco se aplicará la dinamogénesis de los valores para ver qué consecuencias obtendríamos, teniendo como referente el marco normativo español del medio ambiente. En el país de los iberos, el medio ambiente se configura como un principio rector de la política social y económica en el artículo 45 de su Constitución de 1978 que se expresa en términos de un derecho al medio ambiente adecuado para el desarrollo de la persona y el deber de conservarlo ${ }^{32}$.

Observamos en primer lugar que el artículo 45 contiene un mandato dirigido a los poderes públicos de aplicar dicho principio en sus actuaciones administrativas o normativas ${ }^{33} \mathrm{y}$ que si efectivamente debido a su naturaleza de principio rector precisa de una ley de desarrollo para ser alegado ante los tribunales ordinarios como indica el dictado el artículo 53.3 de la Constitución española, puede mantenerse con SERRANO MORENO que

"el artículo 45 es alegable y aplicable ante los tribunales. Lo que el 53.3 quiere decir y no dice es que por sí mismo este artículo no otorga derechos subjetivos públicos y generales, cosa muy distinta es que nos encontrásemos ante una prohibición de alegación y/o aplicación"34.

En este sentido se manifiesta parte de la doctrina que mantiene la nota de fundamentalidad $^{35}$ de este derecho y especialmente MENDEZ ROCASOLANO que a través de la ya mencionada dinamogénesis de los valores consigue justificar la naturaleza de derecho exigible respecto al medio ambiente "traspasando las barreas del positivismo jurídico y ajustar el Derecho a los exigencias del paradigma ecológico". 36

La dinamogénesis de los valores en una herramienta que describe el proceso de reconocimiento de los derechos cuando expresan valores que no se encuentran regulados pero que la sociedad siente como tales y por tanto demanda su protección

La secuencia es la siguiente: ${ }^{37}$

\footnotetext{
${ }^{31}$ VECCIO, Giogio del: Los principios generales del derecho.Trad F. Clemente de Diego. Bosch. Barcelona. 1979. Págs 49, 76 y 122.

${ }^{32}$ En este sentido se manifiestan BELTRAN DE FELIPE, y CANOSAUSERA que consideran am medio como "un interés que, por mandato constitucional, han de proteger los poderes públicos par que lo disfruten los ciudadanos, últimos beneficiarios en su dignidad, de la preservación del entorno" BELTRAN DE FELIPE, Miguel y CANOSAUSERARaul: "Relevancia constitucional del medio ambiente"enNoticias de la Unión Europea $\mathrm{n}^{\circ} 122$ marzo. Edt. CISS. S.A. Valencia.1995. pág 42.

33 ORTEGA ALVAREZ Ibidem Igualmente COBREROS MENDAZONA, E,"Reflexiones sobre la eficacia normativa de los principios rectores de la política social y económica del Estado", Revista Vasca de Administración Pública ,nº 19,1988.

${ }^{34}$ SERRANO MORENO, Jose Luis: "La Constitución ambiental" en Anuario de Derecho Público y estudios políticos. Monográfico: Los derechos fundamentales. $\mathrm{n}^{\circ} 2$. Servicio de Publicaciones de la Universidad de Granada. Granada. 1989-90. Pág 206.

${ }^{35}$ Desde el campo de la filosofía del derecho Vicente BELLVERCAPELLA realiza una notable defensa del derecho al medio como derecho fundamental aceptando la renuncia que debe hacerse a la concepción estricta de tales derechos en Ecología: de las razones a los derechos ,Granada,1994 págs 185-301.

${ }^{36}$ MENDEZ ROCASOLANO, ob,citPág 406.

${ }^{37}$ Esta secuencia ha sido ya utilizada en varias ocasiones para justificar la exigencia de otros derechos como el Derecho al Desarrollo Sostenible por Vladmir OLIVEIRA DA SILVEIRA, y en relación con la soberanía por Alba

Revista de Direito Brasileira | São Paulo, SP | v. 19 | n. 8 | p. 70 - 83 |Jan./Abr. 2018
} 


\begin{tabular}{|l|l|}
\hline Mundo abstracto de los valores & El valor es una entidadabsoluta \\
\hline Sentimiento axiológico de la sociedad & $\begin{array}{l}\text { El valor sesiente valioso, el valor es en la } \\
\text { realidad social.Valen }\end{array}$ \\
\hline $\begin{array}{l}\text { Juridificación del valor (inclusión del } \\
\text { mismo en el ordenamiento jurídico) }\end{array}$ & $\begin{array}{l}\text { El valor se protege y garantiza a través del } \\
\text { Derecho. Los valores debenser }\end{array}$ \\
\hline
\end{tabular}

Cuadro nº 45: Expresión grafica de la dinamogénesis de los valores de María Méndez Rocasolano

En palabras de la discípula de LUCAS VERDÚ y de su querida esposa también profesora Carmen MURILLO DE LA CUEVA ${ }^{38}$, se cumple la afirmación siguiente:

"la cultura contiene valores que cuando son sentidos como tales por la sociedad se convierten en valiosos y el Derecho se encarga de protegerlos y garantizarlos cuando los incluye en el ordenamiento jurídico... así avanza la sociedad que va adecuando la cultura al devenir histórico de forma tal que "si el sentimiento axiológico de la sociedad no tiene un reflejo dentro del Derecho podemos decir que ese Derecho es obsoleto o no satisface los intereses que la sociedad exige, no cumple con su función", 39

Con la profesora volvemos al discurso anterior incorporando a los conceptos de validez, obligatoriedad y eficacia el de vigencia. En este sentido MENDEZ ROCASOLANO repito lo que en otra ocasión indiqué

"puede que nos encontremos con un plexo de valores que "son" porque han sido desvelados por las circunstancias, pero algunos sólo valen y otros deben ser. ...El Derecho capta los valores "sentidos" como tales por la sociedad y los traduce en principios axiológicos normativizados que se imponen a la sociedad a través de las reglas de eficacia validez y vigencia. Lo que socialmente vale lo convierte en un deber ser valioso. Así pues el deber ser valorativo, sería el propio de la eficacia, que significa que los mandatos contenidos en las normas deben ser cumplidos" $"$.

De este modo parafraseando a D. Pablo “emerge la función jurídica protectora de los valores adoptando medidas preventivas y represivas contra su violación" 41

Resuelve la cuestión de la existencia de los valores superando su vinculación con el Derecho indicando que un "valor es cuando la sociedad lo siente, cuando tienevalor para la comunidad, cuando vive en la conciencia social" 42 . El Derecho es un medio que lo garantiza y exige.

La labor instrumental que da al Derecho toma pleno sentido en el caso del conflicto de intereses no normativizados que resuelve superando la laguna legal a partir de los principios y la fundamentación axiológica. En este sentido indica:

FLOREX GAXIOLA, la profesora también lo ha utilizado para fundamentar la exigencia de los derechos de los niños.

${ }^{38}$ En este sentido se recomienda la lectura de María del Carmen MURILLO DE LA CUEVA Y LERDO DE TEJADA, En torno al tridimensionalismo, Ed. Dykinson, 1997, in totum donde podrán encontrar consideraciones completas y destacadas respecto a la apuntada líneas arriba teoría tridimensional por la que el Derecho tiene tres dimensiones vinculadas entre sí : hecho, norma y valor. Sirva el presente para recordarla y mostrar el reconocimiento académico que merece, pues mientras se escriben estas líneas el Señor se la ha llevado junto a su marido a la Gloria eterna.

${ }^{39}$ Pág 145.

${ }^{40}$ Ibidem.

${ }^{41}$ LUCAS VERDÚ.Ibidem,pág 21.

${ }^{42}$ MENDEZ ROCASOLANO Ibidem.

Revista de Direito Brasileira | São Paulo, SP | v. 19 | n. 8 | p. 70 - 83 |Jan./Abr. 2018 
"El ordenamiento constitucional, mediante el artículo 45 reconoce la existencia formal de tal derecho que es de todos. Además, en su dimensión principial el ambiente, cumple con la importante labor de ser objetivo final que dirige la acción de los poderes públicos y condiciona la interpretación del ordenamiento jurídico ${ }^{43}$.Es decir, el Estado queda afectado por el compromiso ambiental a través del mandato directo y finalista que se impone a los poderes públicos. En definitiva, aceptando lo anterior se pondría de manifiesto que "el ordenamiento jurídico, por su propia naturaleza, se resiste a ser congelado en un momento histórico determinado: ordena relaciones de convivencia humana y debe responder a la realidad social de cada momento, como instrumento de progreso y perfeccionamiento" (STC de 16 de marzo de 1981 F jco 5), y por ello se cumpliéndose así la secuencia que antes apuntábamos:

\begin{tabular}{|c|c|}
\hline Mundo abstracto de los valores & El valorecológicoes una entidadabstracta \\
\hline $\begin{array}{c}\text { Sentimiento axiológico de la sociedad que } \\
\text { a partir de los años 50 se adhiere al valor } \\
\text { ecológico. }\end{array}$ & $\begin{array}{c}\text { El valor ecológico o ambiental sesiente } \\
\text { valioso, el valor es en la realidad social. } \\
\text { Surge el interés y la } \\
\text { problemáticaambiental. }\end{array}$ \\
\hline Juridificación del valor (inclusión del \\
mismo en el ordenamiento jurídico) & $\begin{array}{c}\text { El valor se protege y garantiza a través del } \\
\text { Derecho. La Constitución española lo } \\
\text { recoge en el art. 45. }\end{array}$ \\
\hline
\end{tabular}

Pudiera parecer contradictoria la posición que mantenemos de incorporar una norma voluntaria al grupo de las disposiciones obligatorias cuando está probado que estás no se cumplen, aporía que se supera con los beneficios sociales y principalmente económicos que su eficacia produciría y sobre todo cumpliéndose con el valor ecológico o que las normas de gestión ambiental en el sector del turismo representan en su aplicación práctica.

Mantenemos con BOBBIO que los valores y principios impregnan las reglas jurídicas tanto a nivel estructural como funcional ${ }^{44}$, así el proceso al que estarían sujetas las normas de gestión ambiental para poder obtener de ellas un resultado normativo de carácter obligatorio sería el siguiente:

\begin{tabular}{|c|c|c|}
\hline Mundo abstracto de los valores & $\begin{array}{c}\text { El valor de desarrollo } \\
\text { sostenible que vincula la } \\
\text { eficiencia y eficacia } \\
\text { productiva a la protección } \\
\text { ambiental y el valor } \\
\text { ecológico } \text { es un } \\
\text { entidadabstracta }\end{array}$ & $\begin{array}{c}\text { Los valores } \\
\text { vinculados al turismo } \\
\text { como fenómeno } \\
\text { democratico son } \\
\text { igualmente entidades } \\
\text { abstractas }\end{array}$ \\
\hline $\begin{array}{c}\text { Sentimiento axiológico de la } \\
\text { sociedad que a partir de los } \\
\text { años 70 especialmente en el } \\
\text { marco internacional con el } \\
\text { informe Brutland se adhiere al } \\
\text { valor de desarrollo sostenible. }\end{array}$ & $\begin{array}{c}\text { El desarrollo sostenible } \\
\text { sesiente valioso, el valor } \text { es } \\
\text { en la realidad social. Surge } \\
\text { el interés y la }\end{array}$ & $\begin{array}{c}\text { Se sienten valiosos, } \\
\text { los resultado de la } \\
\text { actividad turística } \\
\text { froblemáticade incorporar } \\
\text { medidas reductoras de la } \\
\text { contaminación y los }\end{array}$ \\
$\begin{array}{c}\text { principalmente en el } \\
\text { desarrollo económico } \\
\text { y la puesta en valor }\end{array}$ \\
\cline { 2 - 2 }
\end{tabular}

${ }^{43}$ STC 83/1984 de 27 de julio.

${ }^{44}$ Cfr BOBBIO, Nomberto: Dalla strutturaallafunzione, Ed. di Comunità. Milan. 1977. Tambien PECES BARBA, Gregorio: Los valores superiores. Tecnos. Madrid. 1984. VILAS NOGUEIRA, José: "Los valores superiores del ordenamiento jurídico"enRevista Española de Derecho Constitucional,Año 4, n ${ }^{\circ}$ 12,septiembre- diciembre ,Madrid,1984. 


\begin{tabular}{|c|c|c|}
\hline & $\begin{array}{l}\text { recursos naturales en los } \\
\text { procesos productivos. }\end{array}$ & de destinos \\
\hline $\begin{array}{l}\text { Juridificación del valor } \\
\text { (inclusión del mismo en el } \\
\text { ordenamiento jurídico) }\end{array}$ & $\begin{array}{c}\text { El valor se protege y } \\
\text { garantiza a través del } \\
\text { Derecho. En España en } \\
\text { desarrollo del art. } 45 \text { CE se } \\
\text { dicta la ley de Economía } \\
\text { sostenible. Y se fomenta a } \\
\text { través de políticas de } \\
\text { desarrollo sostenible la } \\
\text { implementación de normas } \\
\text { de gestión ambiental en el } \\
\text { sector productivo (ISO } \\
\text { 14.000 Y REGLAMENTO } \\
\text { EMAS) }\end{array}$ & $\begin{array}{c}\text { Como consecuencia } \\
\text { del impacto antrópico } \\
\text { se buscan } \\
\text { mecanismos que } \\
\text { procuren un eficaz } \\
\text { equilibrio entre el } \\
\text { desarrollo del turismo } \\
\text { y la protección } \\
\text { ambiental donde la } \\
\text { implementación de la } \\
\text { normativa de gestión } \\
\text { tiene protagonismo }\end{array}$ \\
\hline
\end{tabular}

El siguiente paso consiste en definir que tipología de norma sería aquella que no violentara el proceso legislativo democrático a través del cual regimos nuestro comportamiento por los dictados generados por los representantes de la soberanía popular en el seno de las instituciones creadas a tal efecto. Aquí proponemos la fórmula de la delegación legislativa a través de la cual las instituciones locales podrían importar bajo la forma de reglamentos los dictados de las normas voluntarias de Gestión ambiental. De esta forma las exigencias que se dan para el cumplimiento de la normativa ambiental quedarían resueltas. Ciertamente queda responder a la siguiente cuestión ¿Si la normas ambientales no se cumplen con eficacia, porqué incorporamos una más al ordenamiento jurídico? ¿Por qué se considera que estás normas a diferencia de las otras si se van a cumplir?

Estas cuestiones se resuelven con la particularidad propia de las normas de gestión ambiental que no sólo protegen el medio sino que promocionan la productividad de las empresas. Aquí el valor económico actúa como un potente elemento que fomenta la protección del medio natural de los destinos turísticos que no sólo cuentan ya con el valor ecológico sino con un valor económico en cuanto generan empleo y riqueza.

El transfondo sociológico y económico de los valores e intereses en juego participan en el proceso de desarrollo de creación normativo, en la esfera práctica y en la positivización de forma que

"la norma jurídica aparece en relación con una determinada realidad social- que le sirve de orden y sobre la cual, a su vez aquella opera-y en relación con una determinado sistema de valores -que orienta a esa normatividad y pretende, en su caso servirle como fundamento y razón legitimadora ${ }^{45}$.

En un Estado social y democrático de Derecho, corresponde cumplir con los compromisos adquiridos en las campañas electorales y a la sociedad civil ${ }^{46}$ su exigencia para instar a los poderes públicos a realizar actuaciones encaminadas a la transformación social y al

\footnotetext{
${ }^{45}$ DIAZ, Elias: Sociología y filosofía del Derecho,Taurus,Madrid. 1982. Págs. 125 y 126.

${ }^{46}$ GOZALEZ BERNALDEZ hace unas interesantes consideraciones sobre la tecnocratización del medio, que a su juicio se presenta como un grave peligro. Considera necesaria al participación del "hombre de la calle"en los temas ambientales Cfr "Problemas ecológicos de la conservación de medio ambiente" en Conservación del medio ambiente,Revista de la Universidad Complutense no 105,septiembre-octubre 1976. Madrid. 1976. Págs. 171 y 172.
}

Revista de Direito Brasileira | São Paulo, SP | v. 19 | n. 8 | p. 70 - 83 |Jan./Abr. 2018 
cumplimiento con los valores básicos de proteger el medio ambiente ${ }^{47}$, es decir los hábitats donde los ciudadanos desarrollamos nuestras vidas ${ }^{48}$. El impacto del turismo puede ser reconducido hacia un impacto positivo del medio a través de procedimientos y procesos que gestionen adecuadamente la actividad turística.

Campus de Los Jerónimos

\footnotetext{
${ }^{47}$ A juicio de Tomás Ramón FERNANDEZ RODRIGUEZ el derecho al medio es un elemento dinamizador, un factor de cambio y de transformación social de un estado de cosas FERNANDEZ RODRIGUEZ, Tomás Ramón: "Derecho medio ambiente y desarrollo", REDA no 24. Madrid.1980. Págs. 6 y 7.

${ }^{48}$ CANOSA USERA, Raul: "Aspectos constitucionales del derecho ambiental" en Revista de Estudios Políticos, (Nueva Epoca) no 94 Centro de Estudios Constitucionales. Madrid. Octubre diciembre 1996. Pág 92, destaca su dimensión social al indicar que "Un entorno deteriorado impide a todos disfrutarlo y, a la inversa, un medio adecuado beneficia a todos tal y como acontece en los derechos económicos y sociales, la proyección utisocius a compaña a su dimensión utisingulis.
} 